\title{
The Language of Classification in Accounting Texts in the Framework of SFL
}

\author{
Bahtera Sembiring \\ Department of English, Politeknik Negeri Bandung, Bandung, Indonesia \\ E-mail: bahtera.sembiring@polban.ac.id
}

\begin{abstract}
This paper reports the study of language of classification on accounting texts using the Systemic Functional Linguistics (SFL) framework. It focuses on how language of classification is realized structurally on a such text. The studies conducted by Wignell, Martin and Eggins (1993) focusing on physical geography texts and Khorina, Suyatna and Indira (2017) concerning with electronics engineering texts, identified that classification was realized either by intensive or possessive relational process clauses working on attribute mode. In relation to the prior studies, the data were collected from two accounting textbooks used as references by the students of Accounting Department at Politeknik Negeri Bandung (Polban). Both of the types of relational process clauses were found in the texts consisting of 14 clauses classified as intensive and 17 belonging to possessive ones. Both types of the clauses contain attributive relational process. The attributive relational process occuring in intensive relational process clauses is realized solely by verb be. However, the relational process which appears in possessive relational process is realized by several verbs which are break, classify, consist, divide, and include. The implication of this study is not only for modelling English grammar of Accounting texts, but also for translation study.
\end{abstract}

Key words: SFL, classification, intensive relational process clause, possessive relational process clause

\section{INTRODUCTION}

A number of students are reluctant to read references. One of them is textbook. This is due to the fact that the textbook usually contains dense vocabulary and complex sentences. Consequently, many students find difficulties in understanding it. However, reading textbooks is regarded as a compulsory task to do for higher education students. If a student failed in comprehending knowledge of his/her discipline, there would be an impact on his/her study as a whole.

To overcome the difficulties, SFL offers a framework to study their behavior of the language of the textbook. Textbooks as a result of scientific thoughts have certain characteristics. First, a scientist prefers to use jargons among their peers to talk about their discipline. Therefore, there are a lot of terms appearing in their texts which might be 
strange for the students who begin to learn about the discipline. Second, the scientists work a lot with taxonomy or classification. These are two of the characteristics owned by textbooks (Darian, 2003). Classification as one of characteristics of textbooks is realized by relational process clauses as identified by Wignell et al (1993) and Khorina et al (2017). With understanding this, it would be easier to understand textbooks. Therefore, the study addressed two issues:

1. To analyze the type of relational process clauses representing classification in accounting texts.

2. To analyze the kinds of verbs which realize relational process in the clauses.

\section{LITERATURE REVIEW}

\section{Texts}

A text is defined by Halliday and Hasan (1976) as language used without considering the length of the text. The focus of a text is meaning, so a text never occurs solely without context. It is the contexts which characterize its meaning. There are two types of contexts which influence a text: context of culture and context of situation as illustrated by Butt et al in the figure below.

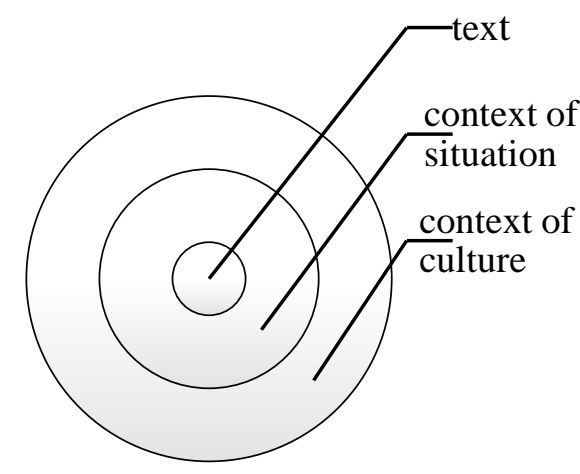

Figure 1 Text in Contexts (Butt et al, 2003: p 2)

Context of situation characterizes a text through elements of register consisting of field, tenor, mode. Field is concerned with the content of the text, and tenor deals with the 
parcipants who are involved in the text while mode refers to the channel of communication used to deliver the text. Hence, these elements will determine the type of text: scientific, narrative, etc. Whereas, context of culture will define the genre of a text. Both of these context work on the level of meaning. The meaning should be realized by grammar to be able to be analyzed as shown in the figure 1.2 proposed by Christie and Derewianka (2010).

\begin{tabular}{|c|c|c|c|}
\hline \multirow{3}{*}{$\begin{array}{l}\mathbf{C} \\
\mathbf{O} \\
\mathbf{N} \\
\mathbf{T} \\
\mathbf{E} \\
\mathbf{X} \\
\mathbf{T}\end{array}$} & \multicolumn{3}{|c|}{$\begin{array}{l}\text { CONTEXT OF CULTURE } \\
\text { Genre as social processes for achieving puposes within the culture }\end{array}$} \\
\hline & \multicolumn{3}{|c|}{$\begin{array}{c}\text { CONTEXT OF SITUATION } \\
\text { Registers as particular configurations as the field, tenor and mode }\end{array}$} \\
\hline & $\begin{array}{c}\text { FIELD } \\
\text { (subject matter or topic) }\end{array}$ & $\begin{array}{c}\text { TENOR } \\
\text { (roles or relationship) }\end{array}$ & $\begin{array}{c}\text { MODE } \\
\text { (a long a continuum from } \\
\text { 'most spoken' to 'most } \\
\text { written') }\end{array}$ \\
\hline & $\begin{array}{l}\text { IDEATIONAL } \\
\text { METAFUNCTION }\end{array}$ & $\begin{array}{l}\text { INTERPERSONAL } \\
\text { METAFUNCTION }\end{array}$ & $\begin{array}{c}\text { TEXTUAL } \\
\text { METAFUNCTION }\end{array}$ \\
\hline $\begin{array}{l}\text { L } \\
\text { A } \\
\text { N } \\
\text { G } \\
\text { U } \\
\text { A } \\
\text { G } \\
\text { E }\end{array}$ & $\begin{array}{l}\quad \text { Clause level } \\
\text { Experiential } \\
\text { metafunction: } \\
\text { The types of processes } \\
\text { involved in the activity, } \\
\text { the participants in the } \\
\text { processes, and the } \\
\text { surrounding } \\
\text { circumstances. } \\
\text { Beyond the clause } \\
\text { Logical metafunction: } \\
\text { The logical relationships } \\
\text { between events (e.g. } \\
\text { where?, when?, how?, } \\
\text { why?) }\end{array}$ & \begin{tabular}{l}
\multicolumn{1}{c}{ Clause level } \\
Resources for interaction (e.g. \\
the MOOD system: questions, \\
statements, commands, \\
offers). \\
Beyond the clause \\
Resources for creating \\
patterns of evaluation and \\
engagement with the \\
audience.
\end{tabular} & $\begin{array}{l}\quad \text { Clause level } \\
\text { Theme and Rheme (the } \\
\text { geginning and end of the } \\
\text { clause) } \\
\text { Beyond the clause } \\
\text { Cohesive devices to form } \\
\text { text }\end{array}$ \\
\hline
\end{tabular}

Figure 2 the Relationship between contexts and language (Christie \& Derewianka, 2010)

In accordance with the three elements of register above, Halliday proposed three famous metafunctions of language. First, ideational metafunction referring to field realized by clause as representation. Then, interpersonal metafunction is based on tenor and realized by clause as exchange. The third metafunction called as textual metafunction is referred to mode and realized by clauses as message. All of these operate on the level 
of grammar. By referring to the figure above, it could be inferred that acounting texts have also certain features in terms of grammar. Martin (1992) stated that scientific texts are dominated by identifying relational process. The other characteristics of this type of text is that it has the language of abstraction so that the learners feel alienated. Consequently, these feature become obstacle in understanding scientific texts as reported by Lemke (1990); Wellington \& Osborne (2001); Fang (2004); Snow (2010); Ahmadi and Bajelani (2012) and Parkinson (2013).

\section{Transitivity}

The clause in transitivity system possesses three components (Halliday, 1994; Halliday and Matthessen, 2004;2014). The components are participants, process and circumstance. Unlike traditional grammar which only has subject, verb, and object or complement in a sentence, the type of participants according to SFL depends on the type of process of the clause as seen in the table below.

Table 1 Type of Process and Participants (Martin, et al, 1997:103)

\begin{tabular}{|l|l|l|}
\hline Type of Process & Types of Participants & $\begin{array}{l}\text { Clause examples } \\
\text { (participants are bold) }\end{array}$ \\
\hline Material & Actor, Goal & she made the coffee \\
\hline Mental & Senser, Phenomenon & she saw the car \\
\hline $\begin{array}{l}\text { Relational : attributive } \\
\text { identifying }\end{array}$ & $\begin{array}{l}\text { Carrier, Attribute } \\
\text { Token, Value }\end{array}$ & $\begin{array}{l}\text { Maggie was strong } \\
\text { Maggie was our leader } \\
\text { she laughed }\end{array}$ \\
\hline Behavioural & Behaver & she replied \\
\hline Verbal & Sayer & $\begin{array}{l}\text { there was once } \text { a beautiful } \\
\text { princess }\end{array}$ \\
\hline Existential & Existent &
\end{tabular}

As seen in the table above, there are six kinds of process in transitivity system. Each process has its own type of participants. Relational process as one of the processes above operates on two types of mode: attributive relational process and identifying relational process. Since SFL always views language in terms of function, the function relational process is to characterize and to identify as stated above. The discussion of relational process is presented below. 


\section{Relational Process}

Relational process is a type of process on Transitivity system (Halliday, 1994; Halliday and Matthiessen, 2004;2014). There are two types of relational process: identifying and attributive. The former serves to identify and the latter is used to characterize. Exemplified by Martin et al (1993, p106) the differences of the types can be seen clearly below.

1) Maxine is energetic. (attributive)

\begin{tabular}{|l|l|l|}
\hline Maxine & is & Energetic \\
\hline Carrier & Process: attributive & Attribute \\
\hline Noun group & Verbal group & Noun group \\
\hline
\end{tabular}

2) Maxine is the goalie (identifying).

\begin{tabular}{|l|l|l|}
\hline Maxine & is & the goalie \\
\hline Token & Process: identifying & Value \\
\hline Noun group & Verbal group & Noun group \\
\hline
\end{tabular}

The table of analysis above shows that relational process clause containing attributive relational process posses the participants as known as Carrier and Attribute. The Attribute represents the attribute of Carrier. The relational process clause containing identifying relational process has two participants called Token and Value. The Value is the representation of Token.

Both the relational process types above work on relational process clauses divided into three types: intensive, possessive, and circumstantial. Two types of relational process clauses: intensive and possessive relational process clauses play as classification (Wignell et al, 1993; Khorina et al, 2017). Both types of relational process clauses are exemplified below. 
3) Physical geography is a science.

\begin{tabular}{|l|l|l|}
\hline Physical georaphy & is & a science \\
\hline Carrier & Process: attributive & Attribute \\
\hline Noun group & Verbal group & Noun group \\
\hline Sub-class & Intensive & Class \\
\hline
\end{tabular}

4) Desert landforms consist mainly of those due to erosion and those due to deposition.

\begin{tabular}{|l|l|l|}
\hline $\begin{array}{l}\text { Desert } \\
\text { landforms }\end{array}$ & consist mainly of & $\begin{array}{l}\text { those due to erosion and those due to } \\
\text { deposition }\end{array}$ \\
\hline Carrier & Process: attributive & Attribute \\
\hline Noun group & Verbal group & Noun group \\
\hline Class & possessive & Sub-class \\
\hline
\end{tabular}

The two tables of analysis imply when classification is realized by intensive relational process clause, Carrier represents sub-class while Attribute represents class. On the other hand, if classification is realized by possessive relational process clause, Carrier represents class and Attribute represents sub-class.

\section{Accounting Texts}

Accounting texts are texts whose field is about accounting. They cover basic principles of accounting and financial reporting, preparing and analyzing financial statements, cost analysis, and the process and politics of budget preparation (https://www.google.com/). With regard to the seven linguistic domains as the features of scientific language identified by Martin and Halliday (2005), it is regarded that accounting texts have their own features. The tenor of the text will be accounting expert and those who learn the discipline. In addition, mode can be either in the form of written or spoken, such as, textbooks or lecturing in class. The relational process clauses play specific roles. One of them serves as classification which is the topic of this paper. 
In conclusion, classification is realized only by attributive relational process in intensive and possessive relational process clauses. Although both types of the clauses own the same kind of relational process, they have diffrences in terms of how the participants represent classification.

\section{METHODOLOGY}

Method used in this study was descriptive analysis. This suggests that the data collected were described and analyzed using the Systemic Functional Linguistics Framework. The data were obtained from two textbooks used as references by Accounting Department students of Politeknik Negeri Bandung. They were Managerial accounting by Garrison, et all (2012) and Managerial Accountig by Hansen, et all (2007). Several steps in analysing the study data were applied. First all clauses containing relative processes were collected. After that, they were classified in terms of the types of relational process clauses: intensive and possessive. Finally the role of classification of the clauses were analyzed. The methods are illustrated in the figure below.

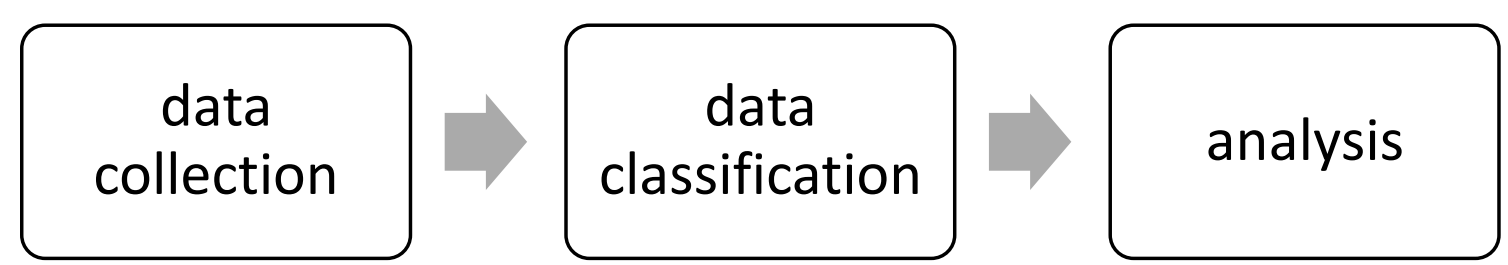

Figure 3 Process of Data Analysis

\section{RESULTS}

It was found that there were 31 clauses classified as classification types. 14 out of 31 were classified as intensive relational process clauses and there were also 17 clauses classified as possessive relational process. Some clauses were taken to be analyzed below.

\section{DISCUSSION}

Classification is realized by relational process clause both intensive and possessive relational process clauses. The samples taken from the textbooks show them. 
(1) A line of credit is an informal agreement

(2) A bond is a formal debt instrument

Clause (1) and (2) belong to intensive relational process clause. The entity of sub-class or kind is represented by Carrier realized by nominal group $A$ line of credit (1) and A bond (2). . Whereas the entity of class is represented by another participant in the clause, that is, Atribute realized by nominal group an informal agreement (1) and a formal debt instrument (2). In other word, Attribute characterizes Carrier through class or Attribute Carrier is a hyponym of Attribute. An attributive relational process as the linker of the participans is realized by verb be as illustrated by the table of analysis below.

Table 2

Analysis of attributive relational process clauses

\begin{tabular}{|l|l|l|}
\hline A line of credit & is & an informal agreement \\
\hline A bond & is & a formal debt instrument \\
\hline Carrier & Process & Attribute \\
\hline Nominal group & Verbal group & Nominal group \\
\hline Sub-class & Intensive & Class \\
\hline
\end{tabular}

To probe that the clause has the role of classification, the interrogative "What is $A$ line of credit/ A bond?" The answer is found in Attribute. This clause is not reversible since the process belongs to attributive type. Other two examples concerning Classification realized by relational process clause, intensive relational process clauses are discussed below. These use the same verb be. However, the verb form used is are as the nominal group of Carrier is plural.

(3) Job-order costing and process costing are two major cost assignment systems.

(4) Setups, inspections, production scheduling, and material handling are examples of batch-level activities.

Clause (3) and (4) also belong to intensive relational process clauses. The entity of subclass or kind is represented by Carrier realized by nominal group Job-order costing and process costing (3) and Setups, inspections, production scheduling, and material handling (4). Whereas the entity of class is represented by another participant in the clause, that is, atribute realized by nominal group two major cost assignment systems (3) and examples of batch-level activities (4). In other word, Attribute characterizes Carrier 
through class or Attribute Carrier is a hyponym of Attribute. An attributive relational process as the linker of the participans is attained by verb be as shown in the table of analysis below.

Table 3

Analysis of role of classification

\begin{tabular}{|c|c|c|}
\hline $\begin{array}{l}\text { Job-order costing and } \\
\text { process costing }\end{array}$ & are & $\begin{array}{l}\text { two major cost assignment } \\
\text { systems }\end{array}$ \\
\hline $\begin{array}{l}\text { Setups, inspections, } \\
\text { production scheduling, and } \\
\text { material handling }\end{array}$ & are & examples of batch-level activities \\
\hline Carrier & Process & Attribute \\
\hline Nominal group & Verbal group & Nominal group \\
\hline Sub-class & Intensive & Class \\
\hline
\end{tabular}

To examine that the clause no. 3 has the role of classification, the interrogative question "What is Job-order costing and process costing?" The answer is found in the Attribute- two major cost assignment systems. It is a similar way to investigate that clause no. 4 contains the role of classification, the interrogative question "What is Setups, inspections, production scheduling, and material handling?" The answer is found in the Attribute- examples of batch-level activities. Those clauses are irreversible since the process belongs to attributive type.

Meanwhile, classification may also be realized by possessive relational process clauses. The relational process remains the same, that is, attributive one but realized by various lexical verbs as seen below.

(5) The conversion costs category can be broken down into direct labor and overhead.

(6) Production costs can be further classified as direct materials, direct labor, and overhead

(7) Product costs consist of direct materials, direct labor, and overhead

(8) A master budget can be divided into operating and financial budgets

(9) The costs of the Photocopying Department include fixed costs of $\$ 26,190$ per year (salaries and machine rental) and variable costs of $\$ 0.023$ per page copied (paper 
and toner).

Clauses (5) - (9) belong to possessive relational process clauses and operate on attributive relational process. But the attributive processes are realized by lexical verbs break, classify, consist, divide, and include as presented in the table below. The attributive relational process realized by lexical verbs break, classify and divide, the verbal groups should be constructed in passive forms found in clauses no. 5 (can be broken down into), 6 (can be further classified as), and 8 (can be divided into). Those passive forms are preceded by verb can and be before the main verbs. Besides, the entity of class is represented by Carrier realized by nominal group The conversion costs category (5), Production costs (6), and A master budget (8). And the entity of sub-class is represented by Attribute realized by nominal group direct labor and overhead (5), direct materials, direct labor, and overhead (6), and operating and financial budgets (8). Whereas the lexical verbs consist of and include stay in active forms as in the clauses no. 7 and 9. The class entity is represented by Carrier caused by nominal group Product costs (7) and The costs of Photocopying Department (9). And the sub-class entity is exhibited by Attribute formed by nominal group direct materials, direct labor, and overhead (7) and fixed costs of $\$ 26,190$ per year (salaries and machine rental) and variable costs of $\$ 0.023$ per page copied (paper and toner)(9).

Table 4

Analysis of possessive relational process clauses

\begin{tabular}{|l|l|l|}
\hline $\begin{array}{l}\text { The conversion costs } \\
\text { category }\end{array}$ & $\begin{array}{l}\text { can be broken } \\
\text { down into }\end{array}$ & direct labor and overhead \\
\hline Production costs & $\begin{array}{l}\text { can be further } \\
\text { classified as }\end{array}$ & direct materials, direct labor, and overhead \\
\hline Product costs & consist of & direct materials, direct labor, and overhead \\
\hline A master budget & into be divided & operating and financial budgets \\
\hline $\begin{array}{l}\text { The costs of the } \\
\text { Photocopying Department }\end{array}$ & include & $\begin{array}{l}\text { fixed costs of \$26,190 per year (salaries } \\
\text { and machine rental) and variable costs of } \\
\$ 0.023 \text { per page copied (paper and toner). }\end{array}$ \\
\hline Carrier & Process & Attribute \\
\hline Nominal group & Verbal group & Nominal group \\
\hline
\end{tabular}




\begin{tabular}{|l|l|l|}
\hline Class & Possessive & Sub-class \\
\hline
\end{tabular}

Furthermore, the nominal groups which realize Attribute contain coordinating connectors indicating equivalency among the things involved in the nominal groups.

Other clauses containing classification roles copied from the text books are to be reviewed as follows:

(10) A production is divided into a unit information section and a cost information section.

(11) A discretionary activity is classified as value-added provided.

The above two clauses are also associated with the possessive relational process clauses and operate on attributive relational process. Yet the attributive processes are realized by lexical verbs classify and divide. Then the attributive relational process realized by the two lexical verbs which are built in passive forms, preceded by verb is plus main verb clssified as and divided into just as delivered in the table below.

Table 5

Analysis of other possessive relational process clauses

\begin{tabular}{|l|l|l|}
\hline A production & is divided into & $\begin{array}{l}\text { a unit information section and a cost } \\
\text { information section }\end{array}$ \\
\hline $\begin{array}{l}\text { A discretionary } \\
\text { activity }\end{array}$ & is classified as & Value- added provided \\
\hline Carrier & Process & Attribute \\
\hline Nominal group & Verbal group & Nominal group \\
\hline Class & Possessive & Sub-class \\
\hline
\end{tabular}

In addition, the entity of class is represented by Carrier realized by nominal group, A production (10) and $A$ discretionary activity (11). Whilst the entity of sub-class is displayed by a unit information section and a cost information section (10) and Valueadded provided Other similar samples of possessive relational process clauses derived from the texts are critical to scrutinize as follows: 
(12) Activity drivers are divided into two general catagories: production drivers (unit level)

and non-unit-level.

(13) Yearly budgets are broken down into quartely and monthly budgets.

The two examples of clauses are members of possessive relational process and operate on attributive relational process. The attribute process is formed by the lexical verbs, divide (12) and classify (13). But the verbs are in passive forms of which begins with verb are and ends with verbs divided and classified as shown clearly in the table below.

Table 6

Analysis of other possessive relational process

\begin{tabular}{|l|l|l|}
\hline Activity drivers & are divided into & $\begin{array}{l}\text { Two general catagories: production drivers } \\
\text { (unit level) and non-unit-level. }\end{array}$ \\
\hline Yearly budgets & $\begin{array}{l}\text { are broken down } \\
\text { into }\end{array}$ & Quartely and monthly budgets \\
\hline Carrier & Process & Attributive \\
\hline Nominal group & Verbal group & Nominal group \\
\hline Class & Possessive & Sub-class \\
\hline
\end{tabular}

The entity of class is constituted by Carrier realized by the nominal groups, activity drivers (12) and Yearly budgets (13). But the sub-class entity is made by nominal groups, Two general catagories: production drivers (unit level) and non-unit-level (12) and Quartely and monthly budgets (13). The last example to be discussed is a clause taken from the text book dealing with possessive relational process and operate on attributive relational process which is (14) The unit information section has two major subdivisions: units to account for and units accounted for. The attributive relational process is organized by a lexical verb has which is the only one clause found with its main verb has. The entity of class is formed by Carrier realized by the nominal group, the unit 
information section (14) and the entity of sub-class

After the data above have been analyzed, it can be summed up that classification is realized by both types of relational process clauses: intensive and possessive. Both of them used attributive relational process type. The attributve relational process in intensive relational process clauses is realized by one kind of verb, ie. be. Moreover, attributve rel ational process in possessive relational process ones is realized by several verbs: break, consist, classify, divide, include, and has.

\section{CONCLUSION}

Based on the discussion above, classification as one role played by scientific language may be realized by relational process. The type of relational process which realized this role is attributive relational process which may occur either in intensive relational process clauses or possessive relational process clauses. When occurring in intensive relational process clauses, the process is realized only by verb be. And entity of class is represented by Attribute. On the other hand, when attributive relational process occurs in possessive clauses, the entity of class appears to be represented by Carrier and nominal groups which realize Attribute always contain coordinating connector and. Then the lexical verbs realizing the attributive process are break, classify, consist, divide, include, and has.

\section{ACKNOWLEDMENT}

This research has been funded by Politeknik Negeri Bandung in 2017 with contract number: Nomor: 654.12/PL1.R7/LT/2017

\section{REFERENCES}

Ahmadi, A and Bajelani, M.R. 2012. Barriers to English for Specific Purposes learning among Iranian University Students. Procedia - Social and Behavioral Sciences 47 (2012) 792-796. Elsevier Ltd. doi:10.1016/j.sbspro.2012.06.736

Butt et al. 2003. Using Functional Grammar: An explorer's guide. Sidney: National Centre for English Language Teaching and Research.

Christie, Frances and Derewianka, Beverly. 2010. School Discourse. London: 
Continuum.

Dull et al. Accounting Information Systems: Foundations in Enterprise Risk Management, 9th edition.

Halliday, M.A.K. 1994. An Introduction to Functional Grammar, $2^{\text {nd }}$ Edition. London: Hodder Education.

----------, M.A.K. 2005. Some Grammatical Problems in Scientific English in Halliday, M.A.K. and Martin, J.R. Eds., Writing Science: Literacy and Discursive Power. Jonathan Webster, Ed. London: Continuum.

----------, M.A.K. and Matthiessen, Christian M.I.M. 2004. An Introduction to Functional Grammar, $3^{\text {rd }}$ Edition. London: Hodder Education.

Hansen et al. 2007. Managerial Accounting, 8th edition.

Khorina, Mulyati et al. 2017. Relational Processes in Scientific Texts: A Functional Grammar Approach. Thesis. Bandung: The Graduate School, Faculty of Science, Universitas Padjadjaran.

Lemke, Jay. 1990. Talking Science: Language, Learning and Values. Wesport: Ablex Publishing

Martin, J.R. 1992. English Text: System and Structure. Amsterdam: John Benjamins Publishing Company

Paltridge, Brian, and Starfield, Sue. 2013. Introduction. In Paltridge, Brian, and Starfield, Sue. (Eds.) The Handbook of English for Specific Purposes, (1-4). Oxford: John Wiley\& Sons, Inc.

Parkinson, Jean. 2013. English for Science and Technology. In Paltridge, Brian, and Starfield, Sue. (Eds.) The Handbook of English for Specific Purposes, (155173). Oxford: John Wiley\& Sons, Inc.

Wellington, Jerry and Osborne, Jonathan. 2001. Language and Literacy in Science Education. Buckingham: Open University Press 